\title{
Komunikasi Bisnis Dalam Usaha Keluarga Etnis Tionghoa
}

\author{
Shella, Wulan Purnama Sari \\ Shella.915150031@stu.untar.ac.id.wulanp@untar.ac.id
}

Fakultas Ilmu Komunikasi Universitas Tarumanagara

\begin{abstract}
The purpose of this research is to examine business communication conducted in Chinese ethnic family businesses and focus on building material shop business. The theory used in this research is the business communication theory, verbal and nonverbal communication, effective business communication, and persuasive communication. This research is conducted with a qualitative method by explaining the findings. Methods of collecting data from this research are interviews, observation, and documenting. Interviews and observations are done to 2 Chinese ethnic entrepreneurs who run a building material shop business. The result of this research shows that persuasive and effective business communication needs to be applied in business.
\end{abstract}

Keywords: Business Communication, Family Business, Chinese Ethnic

\begin{abstract}
Abstrak
Penelitian ini bertujuan untuk meneliti komunikasi bisnis yang dilakukan dalam usaha keluarga etnis Tionghoa dan berfokus pada usaha toko bangunan. Teori yang digunakan dalam penelitian ini adalah teori komunikasi bisnis, komunikasi verbal dan nonverbal, komunikasi bisnis yang efektif, dan komunikasi persuasif. Penelitian ini dilakukan dengan metode kualitatif dengan menjelaskan hasil temuan. Metode pengumpulan data dari penelitian ini adalah wawancara, observasi, dan mendokumentasikan. Wawancara dan observasi dilakukan kepada 2 narasumber pengusaha etnis Tionghoa yang membuka usaha toko bangunan. Hasil dari penelitian ini adalah menjelaskan bahwa komunikasi bisnis yang persuasif dan efektif perlu diterapkan dalam suatu usaha maupun bisnis.
\end{abstract}

Kata Kunci: Komunikasi Bisnis, Bisnis Keluarga, Etnis Tionghoa

\section{Pendahuluan}

Manusia ntuk pertama kalinya perusahaan audit asal Amerika Serikat, Price Waterhouse Cooper (PwC) melakukan survei mengenai bisnis keluarga di Indonesia. Dari hasil survei tersebut, lebih dari 95 persen perusahaan di Indonesia merupakan bisnis keluarga. PwC mendefinisikan bisnis keluarga sebagai perusahaan yang mayoritas hak suaranya berada di tangan pendiri atau orang yang mengakuisisi perusahaan, misalnya pasangan, orang tua, anak atau ahli waris. Setidaknya ada satu perwakilan keluarga yang terlibat di dalam manajemen atau administrasi perusahaan (Agust Supriadi, 2014).

Merujuk pada penelitian yang dilakukan oleh Family Firm Institute untuk the Family Business Review (Hall, 2008), diketahui bahwa hanya 30\% dari keseluruhan perusahaan yang dimiliki oleh keluarga bisa bertahan pada masa transisi antar generasi pada generasi ke-dua, sementara itu hanya $12 \%$ mampu bertahan pada generasi ke-tiga dan hanya 3\% saja yang mampu berkembang sampai pada generasi ke-empat dan seterusnya. 
Melihat dari data diatas, banyak perusahaan di Indonesia yang juga sukses karena peran keluarga para pendirinya bahkan sampai bertahan ke generasi berikutnya. Salah satu contohnya adalah Sampoerna, PT Indofood Sukses Makmur, dan PT Djarum. Perusahaan-perusahaan etnis keluarga Tionghoa yang sudah lama berdiri ini terbukti tangguh karena dapat mengembangkan dan mempertahankan perusahaannya sampai sekarang.

Masyarakat etnis Tionghoa terkenal dengan keahliannya dalam menjalankan sebuah bisnis meskipun etnis Tionghoa di Indonesia ini termasuk kaum minoritas menurut Sensus BPS di tahun 2010.

Pada masa sekarang, banyak sekali etnis Tionghoa yang membuka usaha bisnis keluarga di Indonesia. Salah satu contohnya adalah usaha toko bangunan Jaya Surya yang memiliki 4 saudara yang membuka usaha toko bangunan dalam 1 kota yang sama. Tidak hanya itu, usaha toko bangunan Citra Agung juga telah mengembangkan usaha tersebut sampai kepada generasi kedua. Kedua usaha tersebut telah berjalan hampir 30 tahun lamanya.

Penelitian terdahulu yang peneliti jadikan sebagai acuan dalam menyusun penelitian ini adalah membahas tentang bagaimana teori komunikasi pemasaran dalam mempertahankan loyalitas pelanggan, menelaah bagaimana sebuah perusahaan melakukan regenerasi dengan konsep family business enterprise menjadi family owned business, dan bagaimana komunikasi bisnis yang terjadi sehingga menghasilkan komunikasi yang baik antara pelanggan dan pengusaha.

Tujuan penelitian ini dilakukan untuk mengetahui komunikasi bisnis yang terjadi dalam usaha keluarga etnis Tionghoa pada toko bangunan Jaya Surya dan toko bangunan Citra Agung.

\section{Metode Penelitian}

Penelitian ini menggunakan metode penelitian kualitatif. Menurut Lexy J. Moleong, penelitian kualitatif adalah penelitian yang menelaah peristiwa yang dialami oleh sebuah subjek seperti perilaku, persepsi, motivasi, tindakan secara holistic dengan metode deskripsi dalam bentuk kata dan bahasa (Moleong,2017).

Menurut Gunawan dalam buku Metode Penelitian Kualitatif, studi kasus adalah penelitian yang menempatkan sesuatu atau objek yang diteliti sebagai "kasus". Penelitian studi kasus memusatkan diri secara intensi pada satu objek tertentu yang mempelajarinya sebagai suatu kasus. Subjek penelitian dalam studi kasus ini dapat berupa individu, kelompok, institusi atau masyarakat (Gunawan, 2014).

Metode pengumpulan data yang digunakan pada penelitian ini adalah wawancara, observasi dan dokumen sebagai pelengkap dari penggunaan metode wawancara dan observasi.

Dalam penelitian ini, subyek peneliti yang akan penulis jadikan sebagai narasumber adalah pengusaha yang memiliki latar belakang keturunan Etnis Tionghoa yaitu pemilik usaha toko bangunan Jaya Surya dan pemilik usaha toko bangunan Citra Agung. Sedangkan obyek yang akan diteliti oleh penulis adalah komunikasi bisnis yang terjadi dalam usaha toko bangunan Jaya Surya dan usaha toko bangunan Citra Agung. 


\section{Hasil Temuan dan Diskusi}

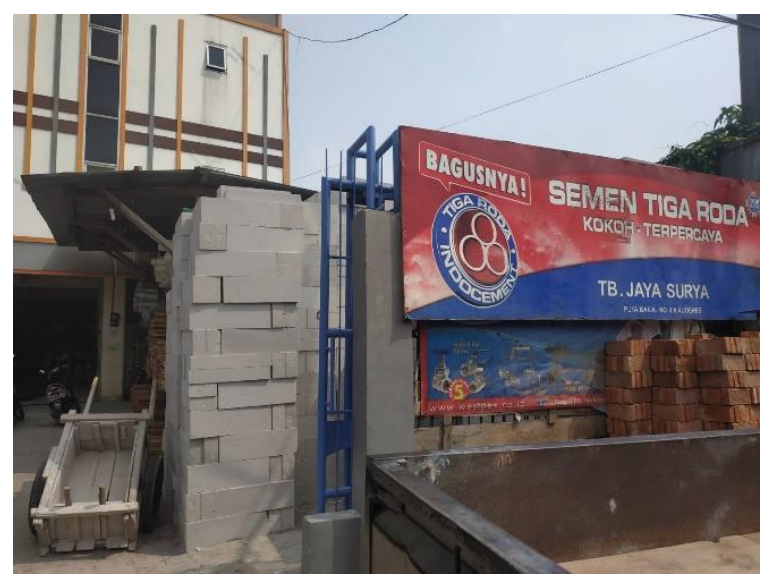

Gambar 1. Toko Bangunan Jaya Surya

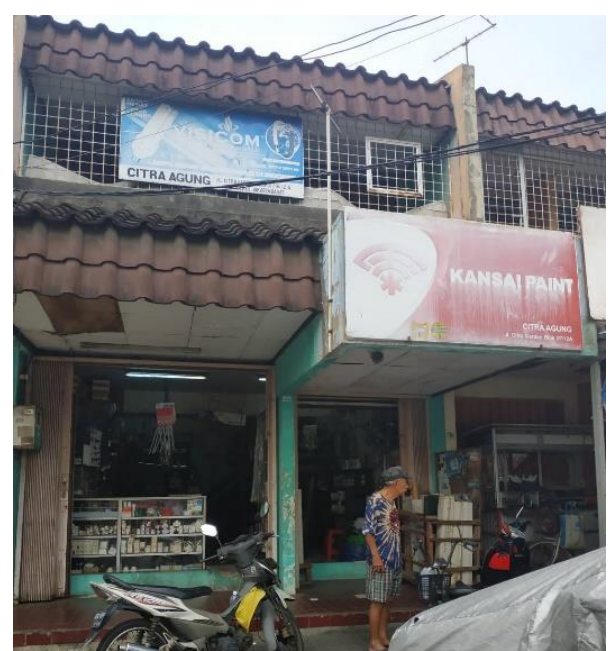

Gambar 2. Toko Bangunan Citra Agung

Komunikasi bisnis yang diteliti memiliki pengertian bahwa komunikasi bisnis adalah komunikasi yang digunakan dalam dunia bisnis yang mencakup berbagai macam bentuk komunikasi baik secara verbal maupun nonverbal untuk menncapai tujuan tertentu. Hal ini sesuai dengan komunikasi bisnis yang terjadi pada toko bangunan Jaya Surya dan toko bangunan Citra Agung.

Toko bangunan Jaya Surya melakukan komunikasi bisnis yang bertujuan untuk memperkenalkan produk yang mereka jual sehingga menciptakan kesepakatan kerja sama yang dapat menghasilkan keuntungan untuk kedua belah pihak. Toko bangunan Jaya Surya selalu menginformasikan hal yang jujur mengenai produk yang dijualnya. Karena menurut Bapak Rudiyanto dan Ibu Liscorianti, kejujuran adalah sesuatu yang paling penting dalam hal berbisnis. Dan dari kejujuran itulah kita akan mendapatkan kepercayaan dari para pelanggan.

Usaha toko bangunan Citra Agung juga melakukan komunikasi bisnis yang sama seperti toko bangunan Jaya Surya. Menurut Pak Tanzil, prinsip utama dalam suatu bisnis adalah kejujuran. Pak Tanzil mengatakan, bahwa dalam usaha memang harus untung tetapi tidak boleh sampai membohongi pelanggan apalagi mengenai masalah kualitas suatu produk yang dijual. 
Setelah menginformasikan, biasanya Bapak Rudiyanto dan Ibu Liscorianti akan mempersuasi pelanggan bahwa barang di tokonya terjamin kualitasnya dan pengiriman pasti cepat. Pak Tanzil pun melakukan proses persuasi setelah memberikan informasi kepada para pelanggannya mengenai produk yang dijual di tokonya.

Toko bangunan Jaya Surya juga memiliki prinsip harus terus maju dan tidak boleh ada yang dirugikan. Hal ini sesuai dengan apa yang dikatakan oleh Purwanto pada buku Komunikasi Bisnis mengenai tujuan dari suatu komunikasi bisnis. Untuk mendapatkan hasil yang menguntungkan untuk kedua pihak, setiap pihak perlu memahami prinsip win-win solution. Hal ini pun sejalan dengan apa yang dilakukan oleh Pak Tanzil dalam menjalankan usahanya. Menurutnya, prinsip win-win solution itu sangat diperlukan sekali dalam setiap bisnis.

Tujuan ketiga dalam komunikasi bisnis adalah melakukan kolaborasi atau kerja sama bisnis antara seseorang dengan orang lain. Hal tersebut telah dilakukan oleh toko bangunan Jaya Surya dengan sesama rekan saudara maupun toko bangunan yang ada di sekitar toko bangunan Jaya Surya tersebut. Kerja sama yang dilakukan oleh toko bangunan Jaya Surya adalah dengan memberikan target pesanan kepada pelanggan. Toko bangunan Citra Agung juga melakukan kolaborasi ataupun kerjasama kepada orang lain untuk terus mempertahankan hubungan yang baik.

Terkadang proses komunikasi yang telah dilakukan tidak berjalan dengan efektif karena tidak mencapai hasil yang baik. Untuk dapat melakukan komunikasi yang efektif diperlukan beberapa persyaratan seperti yang dikatakan oleh Purwanto, yaitu persepsi, ketepatan, kredibilitas, pengendalian, dan keharmonisan/keserasian. Dan hal ini telah dibuktikan oleh kedua usaha toko bangunan ini bahwa mereka telah menjalankan syarat tersebut untuk menjalankan komunikasi bisnis yang efektif.

Seorang komunikator yang cerdas harus dapat memprediksi apakah pesanpesan yang akan sampaikannya dapat diterima oleh komunikan atau tidak. Dalam berkomunikasi dengan pelanggan, biasanya bapak Rudiyanto dan ibu Liscorianti pasti memilih kata-kata yang ringan dan sederhana untuk berkomunikasi supaya dapat dimengerti oleh pelanggan dengan jelas. Bila bertemu dengan pelanggan yang latar budayanya sama, biasanya bapak rudiyanto dan ibu liscorianti pasti akan menggunakan bahasa khek. Dengan itu, membuat pelanggan akan lebih merasa nyaman.

Berbeda dengan toko bangunan Jaya Surya, karena toko bangunan Citra Agung terletak di daerah kompleks, biasanya yang datang pasti orang-orang etnis Tionghoa. Sama seperti bapak Rudiyanto dan ibu Liscorianti, pak Tanzil pun memilih bahasa yang sederhana agar tidak terjadi kesalahpahaman dalam proses jual beli barang tersebut. Bahasa yang digunakan apabila beliau mendapatkan pelanggan yang sama latar belakangnya adalah bahasa hokkian. Tapi apabila beliau mendapatkan pelanggan berbeda latar belakang budayanya, pastinya pak Tanzil akan menggunakan bahasa Indonesia yang baik dan sederhana.

Bapak Rudiyanto dan Pak Tanzil pun sering mendapatkan beberapa pelanggan yang tidak terlalu mengerti tentang bahan-bahan bangunan tersebut, sehingga bahasa yang mereka gunakan harus sederhana agar tidak terjadi salah persepsi yang akan menimbulkan komplain kedepannya. Cara ini dilakukan oleh Bapak Rudiyanto dan Pak Tanzil agar tidak terjadi miscommunications saat melakukan proses komunikasi.

Cara toko bangunan Jaya Surya mendapatkan kepercayaan dari para pelanggan adalah dengan tidak menunda proses pengiriman barang yang sudah dibeli. Berbeda dengan toko bangunan Jaya Surya, cara agar toko bangunan Citra Agung mendapatkan 
kepercayaan dari para pelanggan adalah dengan mempertahankan kualitas dan tidak boleh berbohong kepada pelanggan, dan terus berusaha memberikan yang terbaik.

Dalam berkomunikasi, audiens akan memberikan suatu reaksi atau tanggapan terhadap pesan yang disampaikan. Reaksi mereka dapat membuat komunikator tertawa, menangis, bertindak, mengubah pikiran, atau lemah lembut. Hal ini ditentukan oleh intensitas reaksi yang dilontarkan audiens terhadap apa yang disampaikan oleh komunikator. Sebaliknya, reaksi audiens bergantung pada berhasil atau tidaknya komunikator mengendalikan audiensnya saat melakukan komunikasi.

Cara toko bangunan Jaya Surya meresponi suatu tanggapan yang kurang baik adalah dengan mencari solusinya bersama-sama. Dalam hal ini, menurut Ibu Liscorianti, diskusi itu sangat penting ketika mendapatkan suatu komplain dari pelanggan. Begitu juga dengan Pak Tanzil. Menurutnya, bila mendapatkan komplain, beliau akan mengajak diskusi pelanggan tersebut, lalu mencari solusi ataupun jalan tengahnya supaya kedua belah pihak sama-sama mendapatkan yang baik.

Toko bangunan Jaya Surya selalu memanfaatkan keadaan dan kesempatan untuk dapat menjaga hubungan yang baik antar pelanggan, yaitu pada saat hari raya besar. Cara seperti ini dilakukan agar pelanggan merasa diperhatikan dan dapat saling menjaga hubungan yang baik. Sama seperti toko bangunan Jaya Surya, toko bangunan Citra Agung juga memanfaatkan hari raya besar sebagai bentuk untuk menjalin hubungan yang lebih erat kepada setiap pelanggannya apalagi yang selalu menjadi langganan.

Toko bangunan Jaya Surya dan toko bangunan Citra Agung sama-sama lebih memilih menggunakan komunikasi verbal. Karena menurut mereka, komunikasi verbal merupakan komunikasi yang mudah, sederhana, ringan dan pasti mudah dimengerti oleh orang lain, dan tidak akan terjadi miss komunikasi. Karena, pelanggan yang datang tidak semuanya mengerti tentang bahan bangunan, sehingga, apabila menggunakan bahasa yang rumit ataupun gerak tubuh yang susah dimengerti, akan menimbulkan masalah seperti kesalahan membeli suatu produk ataupun barang.

Mengenai arti nama toko, kedua arti nama toko tersebut tidak memiliki filosofi ataupun pengertian yang khusus. Pada toko bangunan Citra Agung, nama Citra tersebut diambil dari daerah bangunan tersebut dibangun, Citra Garden. Menurut pak Tanzil, nama Citra Agung tercipta agar mudah diingat oleh para pelanggan yang selalu berkunjung ke toko bangunan Citra Agung. Sedangkan pada toko bangunan Jaya Surya, menurut ibu Liscorianti, orang-orang sekitar lebih mengenal toko tersebut dengan sebutan "toko pak Rudi", dikarenakan toko Jaya Surya merupakan toko bangunan pertama yang dibangun didaerah Peta Barat, dan sudah berjalan selama 32 tahun akhirnya membuat warga sekitarnya mengenal toko tersebut dengan sebutan itu.

\section{Simpulan}

Berdasarkan hasil penelitian di atas, kesimpulan yang dapat disimpulkan adalah: Komunikasi bisnis yang dilakukan oleh toko bangunan Jaya Surya dan toko bangunan Citra Agung adalah komunikasi bisnis yang efektif karena telah menjalankan beberapa indikator, yaitu persepsi, ketepatan, kredibilitas, pengendalian, dan keharmonisan dengan para pelanggan. Dengan dilakukannya persyaratan ini, membuat toko bangunan Jaya Surya dan toko bangunan Citra Agung terus dipercaya oleh para pelanggan dan mendapatkan kepercayaan dari para pelanggan. 
Kedua, Toko bangunan Jaya Surya dan toko bangunan Citra Agung telah menjalankan komunikasi bisnis yang baik dan efektif, karena sudah menjalankan tujuan komunikasi bisnis yaitu, informasi (informing), melakukan persuasi (persuading) dan melakukan kolaborasi (collaborating) dengan pelanggan. Dengan melakukan tujuan komunikasi bisnis tersebut, membuat toko bangunan Jaya Surya dan toko bangunan Citra Agung tidak hanya sekedar mendapat kepercayaan dari para pelanggan, tapi juga mendapatkan kepercayaan dari toko bangunan lainnya karena terjalinnya hubungan yang baik antara kedua belah pihak yang saling menguntungkan.

\section{Ucapan Terima Kasih}

Peneliti mengucapkan terima kasih kepada seluruh informan yang telah membantu penulis dalam menyusun penelitian ini. Tak hanya kepada seluruh informan, kepada seluruh dosen dan staf Fakultas Ilmu Komunikasi Tarumanagara yang juga telah memberikan waktu dan ilmunya kepada penulis.

\section{Daftar Pustaka}

Darmawan, Adi. (2016). Studi Komunikasi Bisnis Tiga Pengusaha Etnis Tionghoa Dalam Berkomunikasi Dengan Pelanggan.

Gunawan, Imam. (2014). Metode Penelitian Kualitatif: Teori dan Praktik. Jakarta: Bumi Aksara.

Hagemaru. (2015, Juni 25). Belajar Berdagang dari Etnis Tionghoa. Februari 16, $2019 . \quad$ Kompasiana database. https://www.kompasiana.com/hagemaru_j/550d7a92a33311cd1c2e3c84/bel ajar-berdagang-dari-etnis-tionghoa

Kusniadji, Suherman. (2017). Kegiatan Komunikasi Pemasaran PT. Daya Karya Hutama Dalam Mempertahankan Loyalitas Pelanggan.

Moleong, Lexy. J. (2017). Metodologi Penelitian Kualitatif. Bandung: PT Remaja Rosdakarya.

Purwanto, Djoko. (2006). Komunikasi Bisnis Edisi Ketiga. Jakarta: Erlangga.

Supriadi, Agust. (2014, Desember 2). PwC: 95 Persen Perusahaan Indonesia Adalah Bisnis Keluarga. Februari 16, 2019. Cnnindonesia database. https://www.cnnindonesia.com/ekonomi/20141202100356-92-15176/pwc95-persen-perusahaan-indonesia-adalah-bisnis-keluarga 